\title{
Quaternion-Type Representation for Measuring the Rennet Coagulation Time of Milk by Color Image Sequences Processing
}

\author{
Gamraïkréo Djaowé $^{1}$ Laurent Bitjoka ${ }^{2}$, Yvette Jiokap Nono ${ }^{3}$ \\ 1,2National School of Agro-Industrial Sciences; Energy, Signal, Imaging and Automation Systems Laboratory (LESIA); \\ Modelisation, Image Processing and Application (MOTRIMA) Research Group, the University of Ngaoundere, Cameroon \\ ${ }^{3}$ Department of Chemical Engineering and Environment, IUT, the University of Ngaoundere, Cameroon
}

Corresponding author: Gamraïkréo Djaowé

\begin{abstract}
The determination of the rennet coagulation time of milk by image sequences processing was performed using a computer vision system (CVS), consisting of a computer coupled with a transmitted light microscope equipped with a digital camera. Algorithms implemented with Matlab 2014 encoded the color image as a quaternion, computed and analyzed the histogram peak. The evolution of this last parameter was monitored as a function of the milk coagulation time, for different concentrations of calcium chloride $(0.01-0.03 \mathrm{M})$ and for coagulation temperatures varying between 30 and $36^{\circ} \mathrm{C}$. No statistically significant difference was observed in the measurements of the rennet coagulation time, neither by the Berridge method nor by the analysis of the image sequences, except for those at $36^{\circ} \mathrm{C}$. The association of the optical microscopic method and the analysis of image sequences by a quaternion-type representation, made it possible to identify optical changes during gel formation and to accurately determine the rennet coagulation time of milk.
\end{abstract}

KEYWORDS: Image Sequences Analysis, Quaternions, Color Histogram, Histogram Peak, Optical Sensor, Rennet Milk Coagulation Time.

\section{INTRODUCTION}

The coagulation of milk is one of the most critical steps in cheese making, as it considerably influences the cheese yield as well as the quality of the product obtained [1, 2]. Monitoring the whole process of milk curd formation is a constant preoccupation for dairy researchers and cheese companies. Several methods have been proposed to control rennet coagulation of milk such as ultrasonic sensing methods which gained a real potential to control rennet coagulation of milk. It consists of propagating, in a quantity of milk, two types of sound waves with a certain frequency: shear and longitudinal waves [3]. In an aqueous solution, shear wave is damped, so only longitudinal wave can be used. Gunasekaran and Ay [4] dealt with ultrasounds to determine coagulum cutting time. Nassar et al. [5] used low-frequency ultrasonic technique to monitor milk coagulation time. Izbaim et al. [6] also, used ultrasounds to control the fermentation process of milk during yoghourt processing. Castillo Manuel [7] proposed a classification of some techniques used to monitor milk coagulation and/or the curd firmness. Klandar et al. [8] compared five methods developed, such as Berridge test, dynamic small amplitude oscillatory rheometer (DSAOR), near-infrared (NIR), piezoelectric rheometer and NIR spectroscopy, to control milk coagulation by following the rennet coagulation of two types of reconstituted skim milk. Conventionally, micelle aggregation was visualized by macroscopic changes and measured using the method of Berridge [9]. Kübarsepp et al. [1] also controlled milk coagulation using Formagraph. The Formagraph, based on the drag force technique, was the first mechanical off-line instrument widely used. It is formed by a pendulum plunged into a bowl containing renneted milk as described by McMahon and Brown [10]. The clotting of milk is plotted on a photo sensible paper moving at the rate of $2 \mathrm{~mm}$ per min. It was capable to monitor rheological changes during milk coagulation, but its intrusive behavior was a drawback. Karacheviev et al. [11] evaluated the possibility for modelling milk coagulation kinetics using enzymes with different concentrations. Rheological devices such as the lowamplitude dynamic rheometer oscillatory provide very useful information on the gel formation process [12]. This indirect method, considered as a reference one, is often used to control rennet coagulation of milk. O'Callaghan et al. [13] successfully assessed rennet-induced coagulation of milk using a tuning-fork and torsional probes. Nevertheless, both devices were associated with high-frequency motion (from 10 to $50 \mathrm{~Hz}$, respectively), which could disturb the coagulation process [8]. Another mechanical instrument like the Foodtexture Puff Device was used by Bamelis and De Baerdemaeker [14] to determine texture in order to evaluate milk coagulation. The Foodtexture Puff Device measures the dynamic deformation of the surface of milk during 
coagulation after applying an air puff directed on this surface. A thermal on-line method, the hot wire probe, was particularly efficient at predicting gel time [15-17]. It is based on the hot wire probe plunged in the renneted milk, but it turned out to be unsuitable for monitoring the evolution of firmness.

Changes of the optical properties of milk during coagulation have permitted to develop several devices, more particularly since optical fiber became widespread [15]. The Optigraph is a device invented by Ysebaert society to control milk coagulation and used by Kübarsepp et al. [1]. It measures optical infra-red signal attenuation through milk sample during coagulation and gives time of coagulation and the firmness of coagulum. Klandar et al. [8] have signaled that optical methods such as light absorbance, transmission and reflectance over visible and near-infrared wavelengths, were employed to assess milk coagulation. Fagan et al. [18] have developed a light backscatter sensor technology for online monitoring milk coagulation and whey separation. For the online monitoring of fresh goat cheese during coagulation and syneresis, Rovira et al. [19] used a light backscatter sensor with a large field of view (LFV). Pytel et al. [20] compared two different methods (the visual method and the nephelo-turbidimetry method) for determination of rennet coagulation time. Beux et al. [21] reported that the milk coagulation capacity can be measured by means of optical devices, such as Near-Infrared and Mid-Infrared Spectroscopy. A non-destructive optical microscopic method was proposed by Lagaude et al. [22], to determine visual aggregation and rheometric gel times and to observe simultaneously structural changes during rennet-induced milk coagulation by images processing. As casein micelles cannot be visualized with an optical microscope, the focusing was realized on a bubble of air presenting a diameter of 100 $\mu \mathrm{m}$. The resolution of the optical microscopic observation was sufficient to provide significant information about the formation of the gel network. However, images used were binary images acquired with a rate of one image every two min, which could lead to unsuitable surveying dynamic phenomenon and loss of some adequate information.

Several authors mentioned that automatic tracking of changes in dynamic objects can be surveyed using image sequences [23-28]. For this reason and because color processing is needed everywhere for new technologies, Djaowé et al. [29] studied the kinetic of milk coagulation using color image sequences with a rate of $1 \mathrm{image} / \mathrm{s}$, so as to take into account the color information. But the approach to deal with color images was to process each R, G, B channel of the color image separately. The output vector will rarely be one of the input vector, which yields false color appearance, as reported by Lambert and Chanussot [30], hence the need to look for other approaches to produce visually pleasing color images. A quite recent successful approach in color image processing consists to encode the three R, G, B channel components on the three imaginary parts of a quaternion [31-33]. The main advantages of the use of quaternion-type representation is that: i) a color image can be treated as a vector field [34], ii) The holistic, compact processing of vector-valued signals that are a function of one or more independent parameters (e.g. time, location, physical quantities) [35]. Here, the dimension of the algebra must be chosen in compliance with the dimension of the signal vector. This means that each vector-sample is treated as a whole rather than treating its components separately. Classically, the reason for this is that the sample as a whole conveys information (direction in vector space) that is lost if the components of the sample are processed independently [35]. To our knowledge, the quaternionic representation of the parameters of color image sequences, to determine the coagulation time of milk, has not yet been studied. Taking into account the technological difficulties in determining the accurate coagulation time of renneted milk, the objective of the present work is therefore, to assess this parameter by analysis of image sequences using a quaternion-type color histogram representation.

The rest of this article is organized as follows. First, we discussed some techniques previously developed to control milk coagulation. Then, the quaternion algebra is presented, so as to understand the color representation based on the quaternionic model, followed by the method of images sequence analysis developed using color histogram feature. We then presented results and discussion related to rennet milk coagulation times obtained by image sequences analysis, compared with the reference method of Berridge, and finally the article is concluded.

\section{MATERIALS AND METHODS}

\subsection{Milk preparation and renneting}

\subsubsection{Raw cow milk collection and physicochemical characterization}

Our experimental raw cow milk used was freshly provided by a breeder, less than an hour after milking, from Ngaoundere $\left(7^{\circ} 21^{\prime} \mathrm{N}\right.$ and $\left.13^{\circ} 33^{\prime} \mathrm{E}\right)$ in the Adamawa region of Cameroon. Elevation in Ngaoundere ranges from 900 to $1100 \mathrm{~m}$ above mean sea level. Once in the laboratory, the milk sample was left to stand for $2 \mathrm{~h}$ at $18^{\circ} \mathrm{C}$ before using [36]. Physico-chemical parameters (Proteins, fat content, dry matter, ash, $\mathrm{pH}$ and water content) of our raw cow milk were determined in $100 \mathrm{~g}$ of milk according to the experimental protocol described by Mahieddine et al. [37]. $\mathrm{pH}$ was $6.98 \pm 0.08$, close to $\mathrm{pH}$ obtained by Edima et al (2013) [38] when analysing milk quality from Adamawa region. Water content was $82.76 \pm 0.08 \%$, not far away from values obtained by Adetunji and Babalobi [39]. Proteins, fat rate, ash and dry matter were $3.89 \pm 0.21$, $3.25 \pm 0.01,0.56 \pm 007$ and $17.23 \pm 0.09$ respectively.

\subsubsection{Reconstitution of skimmed milk powder}

A control milk sample as a commercial low-heat skimmed milk powder (Régilait, Saint-Martin-Belle-Roche, France) was 


\section{Processing"}

dissolved in distilled water $\left(120 \mathrm{~g} \mathrm{~L}^{-1}\right)$ and supplemented with (0.01, 0.02 or 0.03$) \mathrm{M}\left(\mathrm{CaCl}_{2}, 2 \mathrm{H}_{2} 0\right)$. The reconstituted skimmed milk was stirred for $30 \mathrm{~min}$ at $20^{\circ} \mathrm{C}$ and left to stand for $2 \mathrm{~h}$. Before using, it was stored for $2 \mathrm{~h}$ at $20^{\circ} \mathrm{C}$ to restore mineral equilibrium and then for $30 \mathrm{~min}$ at the experimental temperatures $\left(30^{\circ} \mathrm{C}, 33^{\circ} \mathrm{C}, 36^{\circ} \mathrm{C}\right)[22]$.

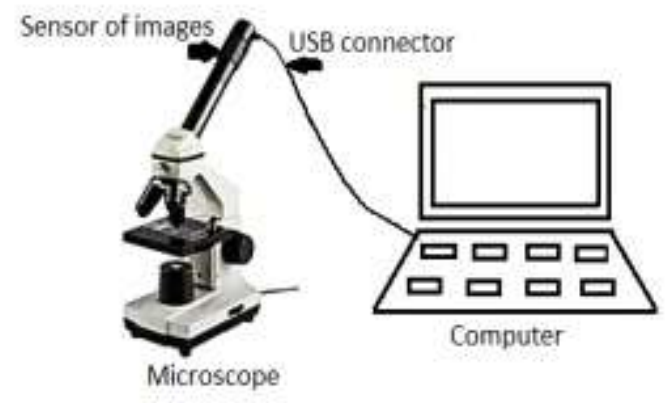

Figure 1: Experimental setup for capturing microscopic image sequences.

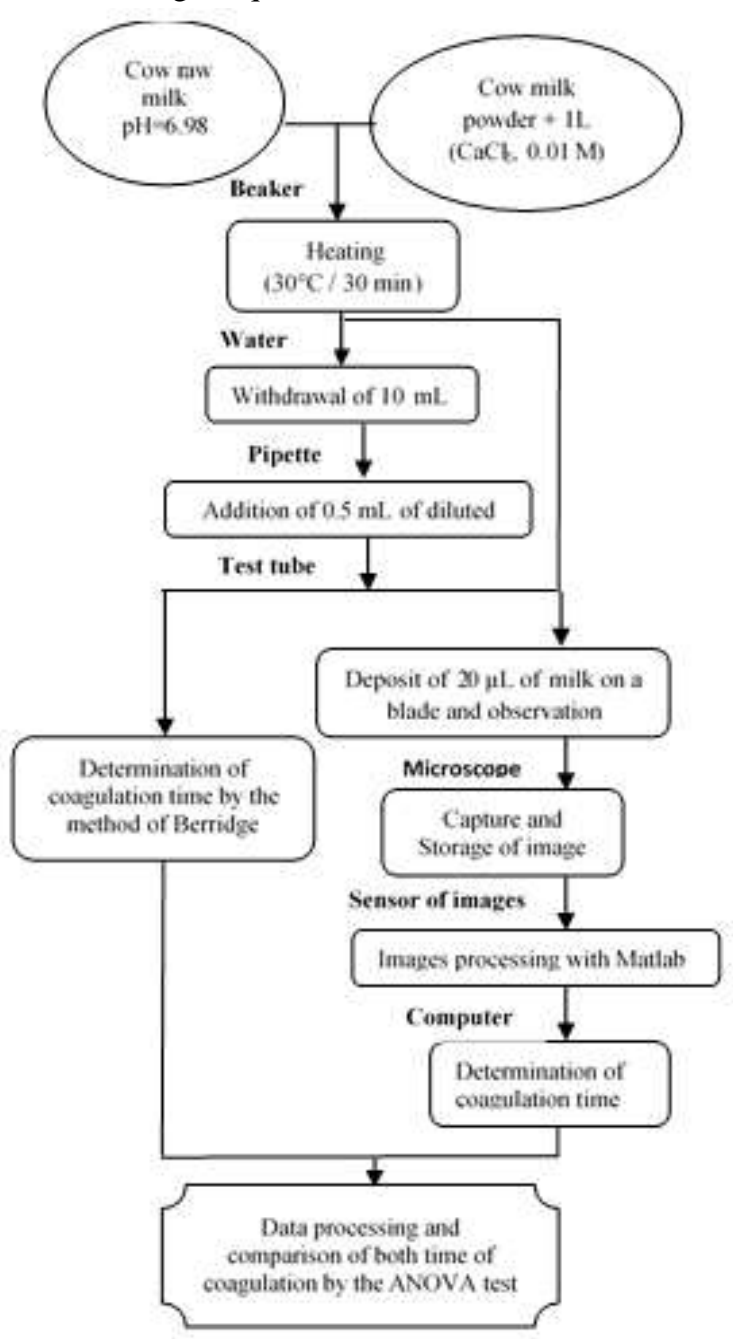

Figure 2: Flow Chart for experimental design of rennetinduced milk coagulation and image sequence processing.

\subsubsection{Milk renneting}

$0.5 \mathrm{~g}$ of rennet $(1 / 10,000$ strength; $99.5 \%$ of activity due to the chymosin, the Etablissement Boll, Arpajon, France) was diluted in $10 \mathrm{~mL}$ of distilled water before addition in milk. 0.5 $\mathrm{mL}$ of rennet was added in $10 \mathrm{~mL}$ of milk placed in a glass tube and vigorously mixed for $30 \mathrm{~s}$. Three levels of coagulation temperature $\left(30^{\circ} \mathrm{C}, 33^{\circ} \mathrm{C}, 36^{\circ} \mathrm{C}\right), \mathrm{CaCl}_{2}$ content $(0.01,0.02$, $0.03) \mathrm{M}$ and rennet quantity $(0.3,0.5,0.7) \mathrm{mL}$ were combined, taking into account real operating ranges. All experiments were carried out in triplicate.

\subsection{Milk clotting assessment methods description}

2.2.1 Renneted milk microscopic image sequences acquisition

A transmitted light optical microscope (Biolux AL, 20x $1280 \times, 220$ - 5.5 VS, 200 MA, Meade Instruments Europe GMBH \& Co. KG, Rhede/Westf., Guetenbergstr.2, Germany) equipped with a digital photograph camera (resolution $640 \times 480$ pixels) connected to a HP computer type $(2.20 \mathrm{GHz}, 2.99 \mathrm{~Gb}$ RAM, 240 Gb DD, Hewlett-Packard Company) was used to observe milk aggregate during renneted milk coagulation (Fig. 1). Rennet-induced milk coagulation and images processing were carried out according to the chart flow in Fig. 2. A sample of rennet-induced milk $(20 \mu \mathrm{L})$ was placed on a microscopic slide covered with a cover slide for examination. The image sequences were recorded for determined times at the same magnification $(40 \times)$ for each sample and were examined by image analysis to identify the histogram peak using Matlab software (2014). As casein micelles cannot be visualized with an optical microscope, the focusing was realized on light passing through milk and captured as images with a rate of 30 image/s. The acquisition process of milk image sequences was interrupted at determined time after the coagulation time was observed by the method of Berridge; depending on rennet level, added calcium and assay temperature.

\subsubsection{Milk image sequences processing}

\subsubsection{Quaternion-type color image histogram representation}

A quaternion $Q \in H$ ( $H$ refers to Hamilton who was first to discover this number) is a generalized complex number defined as:

$Q=q_{0}+q_{1} i+q_{2} j+q_{3} k$

where $q_{0}, q_{1}, q_{2}$ and $q_{3}$ are real numbers; $i, j$ and $k$ are three imaginary units obeying following rules:

$i^{2}=j^{2}=k^{2}=i j k=-1$

$i j=-j i=k ; j k=-k j=i$ and $k i=-i k=j$

The conjugate and modulus of a quaternion are respectively defined by:

$Q^{*}=q_{0}-q_{1} i-q_{2} j-q_{3} k$

$|Q|=\left(q_{0}^{2}+q_{1}^{2}+q_{2}^{2}+q_{3}^{2}\right)^{1 / 2}$

2.2.1.3. Milk image sequences analysis and color histogram determination

Images were analyzed following the block diagram shown in Figs. 3a, b. Rennet-induced milk coagulation images analysis in this paper was based on histogram images analysis. The procedure included two main parts: RGB histogram determination using quaternion algebra and color attributes definition and determination. 


\subsection{RGB histogram image determination}

The histogram of each channel of a color image was calculated by the following relation:

$h(m)=N_{m}$

where $N_{m}$ is the number of pixels corresponding to $\mathrm{m} \in[0$, 255], the gray level in an image.

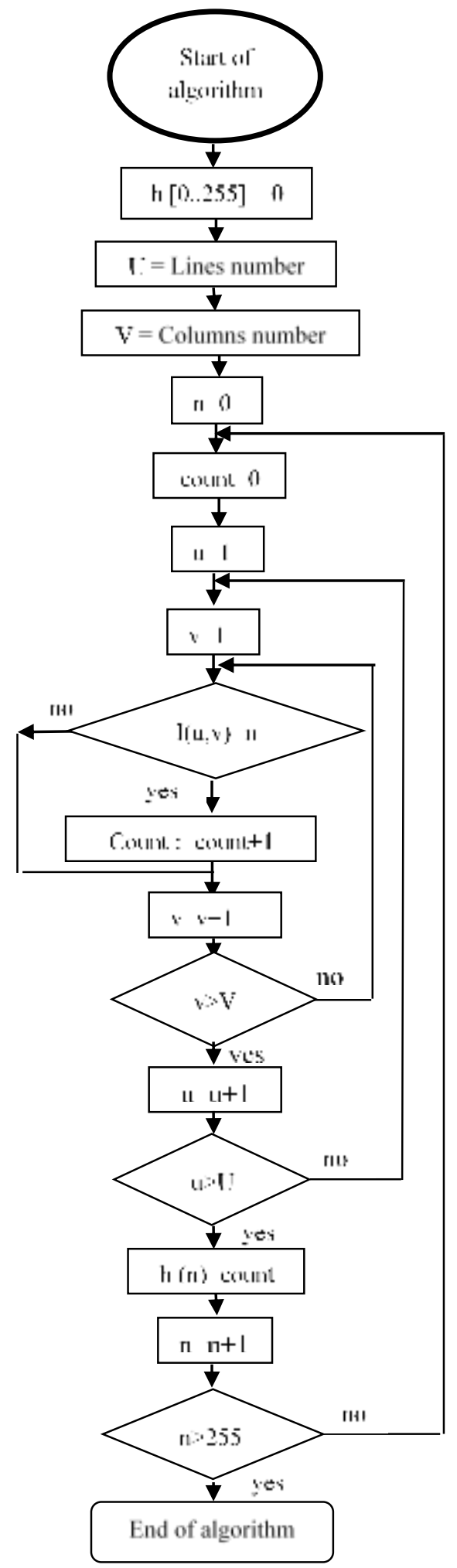

Figure 3a: Algorithm for computing the color channel histogram $\mathrm{h}$ of an image.
Let $I^{R G B}$ be a color image with the spatial resolution of $\mathrm{N} \times \mathrm{M}$ pixels. In this way; it is represented by a set of $\mathrm{N} \times \mathrm{M}$ matrix related to each color channel:

$I^{R G B}(x, y)=\left(I^{R}(x, y), I^{G}(x, y), I^{B}(x, y)\right)$

where $\mathrm{x}=1,2, \ldots, \mathrm{N}$ and $\mathrm{y}=1,2, \ldots, \mathrm{M}$ are the spatial coordinates of the $\mathrm{I}^{\mathrm{RGB}}$ image; $I^{R}, I^{G}$ and $I^{B}$ represent the red, green and blue channels of the color image, respectively.

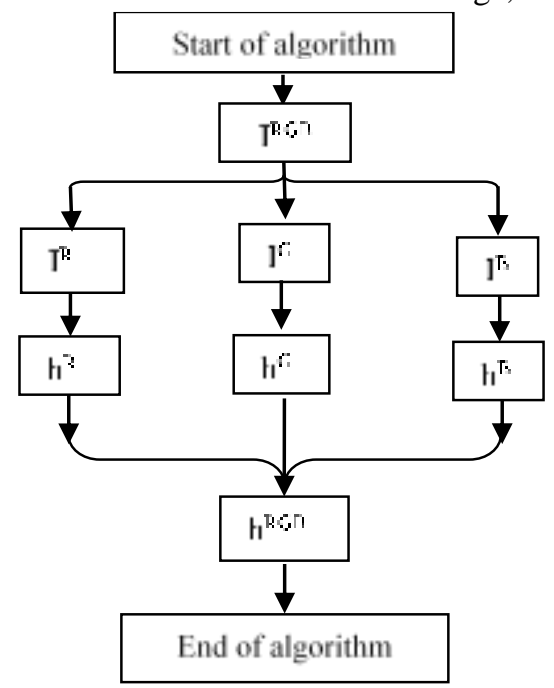

Figure 3b: Algorithm for computing the color image histogram encoded using quaternion

\subsection{Quaternion-type RGB histogram image representation}

Histogram of each color channel of an image was computed according to the algorithm described on the Fig.3a. RGB histogram $\left(h^{R G B}\right)$ of the entire color image was encoded as a quaternion as shown in Fig. $3 \mathrm{~b}$ as follow:

$h^{R G B}(m)=h^{R}(m) i+h^{G}(m) j+h^{B}(m) k$

where $h^{R}, h^{G}$ and $h^{B}$ represent the red, green and blue histogram of each channel of the color image respectively, and $i, j, k$ defined by relations (2) and (3).

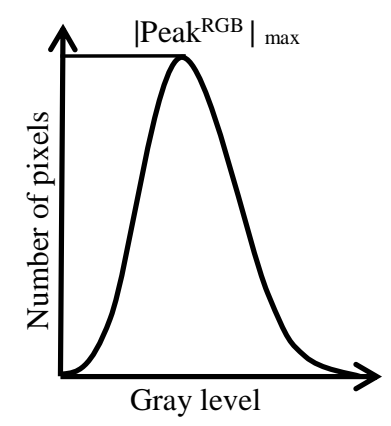

Figure 4a: Feature definition on histogram of an image

\subsection{Quaternion-type RGB histogram image feature determination}

One feature was defined and determined on the modulus of the quaternionic color histogram, computed according to relation (9):

$\left|h^{R G B}\right|=\left(\left(h^{R}\right)^{2}+\left(h^{G}\right)^{2}+\left(h^{B}\right)^{2}\right)^{1 / 2}$ 


\section{Processing"}

This feature was the histogram peak denoted Peak $k^{R G B}$ as shown in Fig. 4a and computed according to the flow chart algorithm described in Figs. 4b, c for image sequences.

$\operatorname{Peak}^{R G B}=\left|h^{R G B}\right|_{\max }$

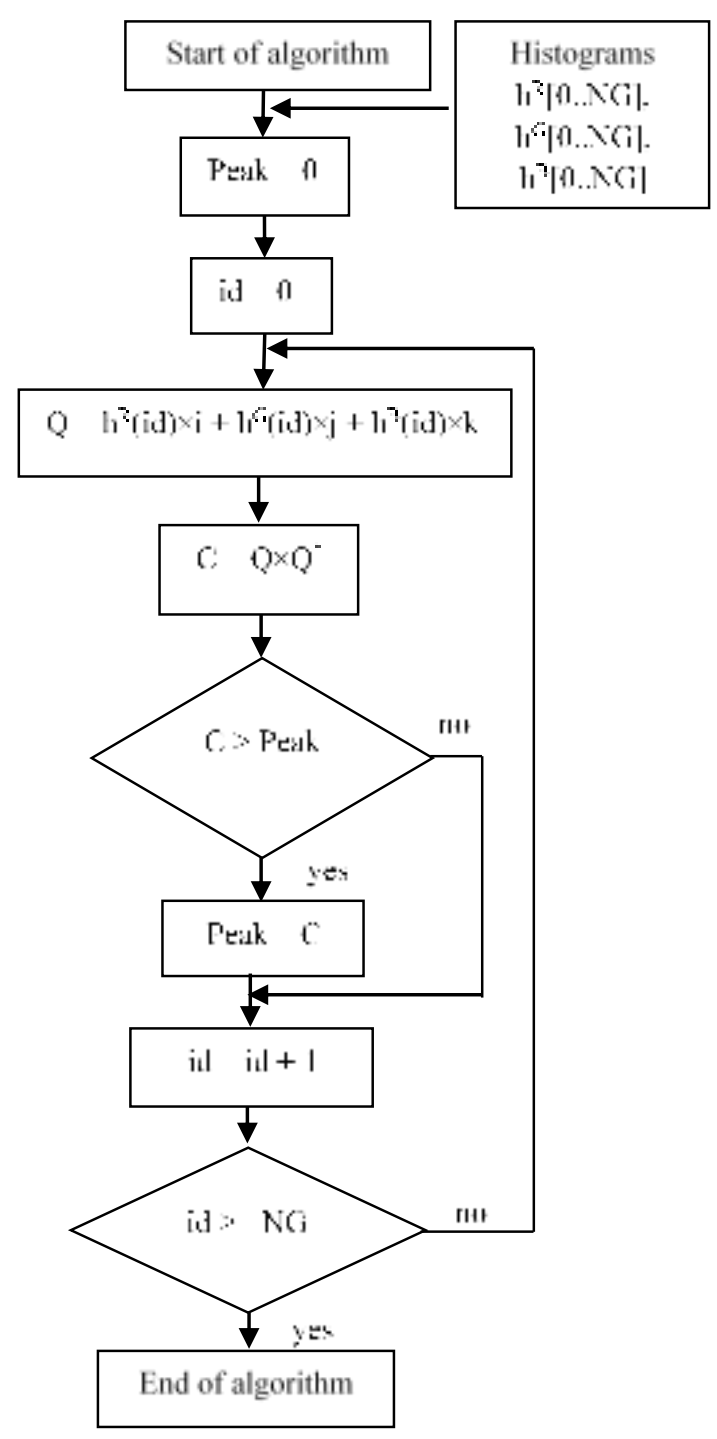

Figure 4b: Algorithm for computing the peak of histogram of an image with quaternion modeling of histogram's vector

\subsection{Histogram peak in image sequences modelling}

All Data (change in the histogram peak as a function of coagulation time) were means values of three replicate experiments produced to provide information on the kinetic parameters which characterize the kinetic model currently used to describe milk coagulation. Data were fitted with SigmaPlot 2012. The output of this analysis is expressed by a curve whose width decreases with the curd firmness. The model of type «four-parameter logistic equation» is a sigmoid $\left(\mathrm{R}^{2}>0.9\right)$ :

$\operatorname{Peak}(t)=$ Peak $_{\text {min }}+\frac{\text { Peak }_{\text {max }}-\text { Peak }_{\text {min }}}{1+\left(\frac{t}{T_{C}}\right)^{\beta}}$

where $t$ represents the time, $T_{C}$ is the corresponding time to the apparition of first flocks in the test tube. Peak $k_{\max }$ and Peak $k_{\text {min }}$ are the maximum and the minimum of the number of pixels respectively, and $\beta$ describes the slope of the curve.

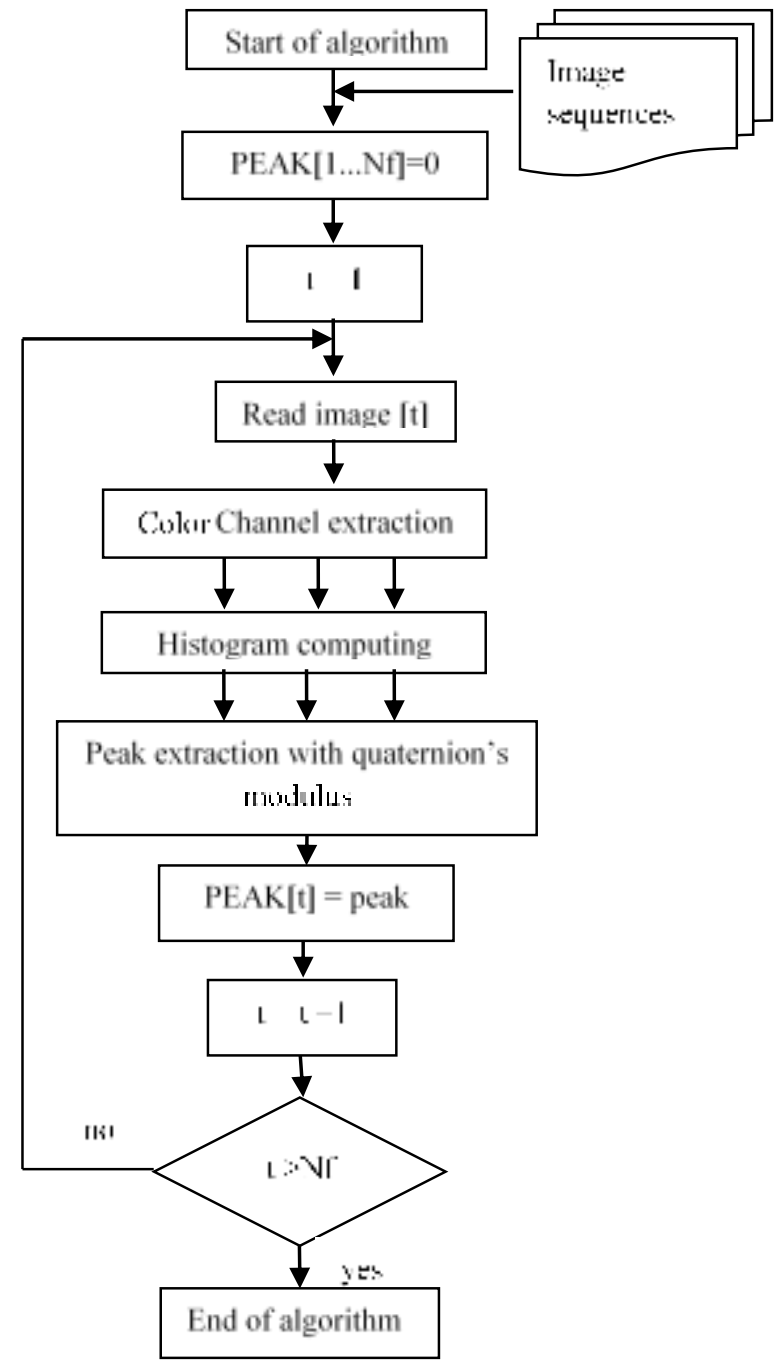

Figure 4c: Algorithm for computing the peak of histogram of milk's sequence of images.

\subsection{Milk clotting time calculation according to image sequences analysis}

As image sequences were acquired with a rate of 30 images/s, the time of coagulation depends on the number of images at the moment of coagulation:

$T_{C}=\frac{N_{C}}{30}$

where $N_{C}$ is the corresponding number of images to the apparition of first flocks in the test tube.

2.2.2. Milk clotting time according to the method of Berridge

The reference method of Berridge consists of observing the coagulation of milk in a test tube. It was carried out by putting $10 \mathrm{~mL}$ of milk and $0.5 \mathrm{~mL}$ of coagulant solution in a test tube plunged in a water bath at $30^{\circ} \mathrm{C}$ [9]. The time of coagulation $\left(\mathrm{T}_{\mathrm{C}}\right)$ is the period elapsed between the introduction of the rennet in the test tube and the moment where a thin film begins to form itself on the inner side of the tube. 
2.3. Effects of rennet level, calcium level and assay temperature on rennet coagulability of milk

To test the effect of rennet level on milk coagulation, the 0.01 $\mathrm{M}$ calcium-supplemented our raw cow milk and the control skim milk powder were used and incubated for $1 \mathrm{~h}$ at $30^{\circ} \mathrm{C}$. Before use, raw cow milk and skim milk substrates supplemented were treated with three different rennet quantities $(0.3,0.5$ or 0.7$) \mathrm{mL}$.

To test the effect of calcium level on rennet coagulation, raw cow milk and skim milk substrates supplemented with $0.01,0.02$ and $0.03 \mathrm{M}$ calcium were prepared as described in Section 2.1.1. Before use, samples were incubated for $1 \mathrm{~h}$ at $30^{\circ} \mathrm{C}$.

To test the effect of assay temperature on rennet coagulability, the $0.01 \mathrm{M}$ calcium-supplemented raw cow milk and skim milk were used. Before use, samples were incubated for $1 \mathrm{~h}$ at the experimental temperatures, i.e. $30^{\circ} \mathrm{C}, 33^{\circ} \mathrm{C}$, or $36^{\circ} \mathrm{C}$, to restore the mineral equilibrium.

\subsection{Statistical analysis}

All experimental data were presented as the means of three independent experiments. Standard deviations were calculated using Excel software 2010 (Microsoft, Redmond, WA, USA) and ANOVA test was carried out using Statgraphics Centurion XVI (16.1.11). Curves fitting was performed using sigmaplot 2012.

\section{RESULTS AND DISCUSSION}

Standardization of the microscopic parameters including the lighting, the luminosity and the magnification was optimized to obtain good sensitivity and repeatability of the images. Before images acquisition, microscope and camera were left to stand on for $1 \mathrm{~h}$ to reach the thermal stability of the system and to avoid some variation while acquiring many images [40].

3.1. Histogram peak in milk image sequences without rennet

Fig. 5 shows a relatively constant variation of the histogram peak in milk image sequences. The fluctuations of the histogram peak around mean value with Standard Deviation of $20042 \pm 1767$ can be related to brownian agitation of the colloidal particles of milk. All particles in milk are subject to random motion caused by their thermal energy. Brownian motion is one of mechanical properties of colloid particles [41] that causes scattering light intensity by milk particles.

3.2. Histogram peak in rennet-induced milk image sequences

For rennet coagulation measured under the chosen microscopic conditions (40 $\times$ magnification), the changes in the histogram peak were followed as a function of the coagulation time of cow milk and skim milk powder. Figs. 6a, b show curves of variation of the RGB color histogram peak in images milk coagulation supplemented with $0.01 \mathrm{M}$ calcium for three rates of the rennet $(0.3 \mathrm{~mL}, 0.5$ and $0.7 \mathrm{~mL})$ at $30^{\circ} \mathrm{C}$.

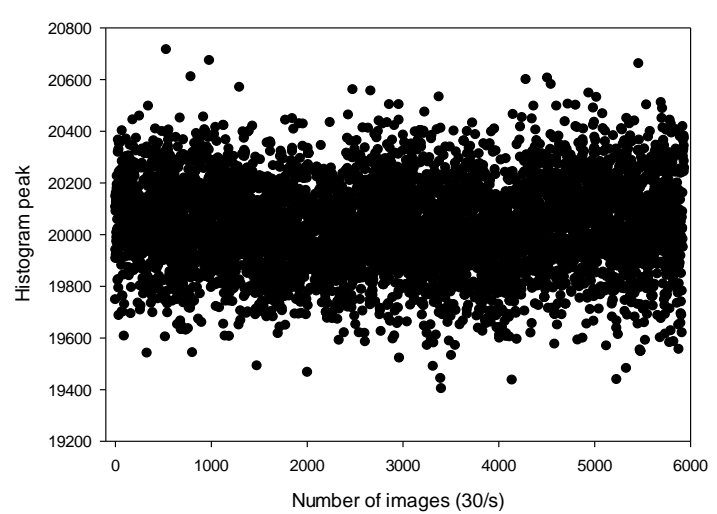

Figure 5: Evolution of the maximum numberof pixels in not rennet-induced milk images
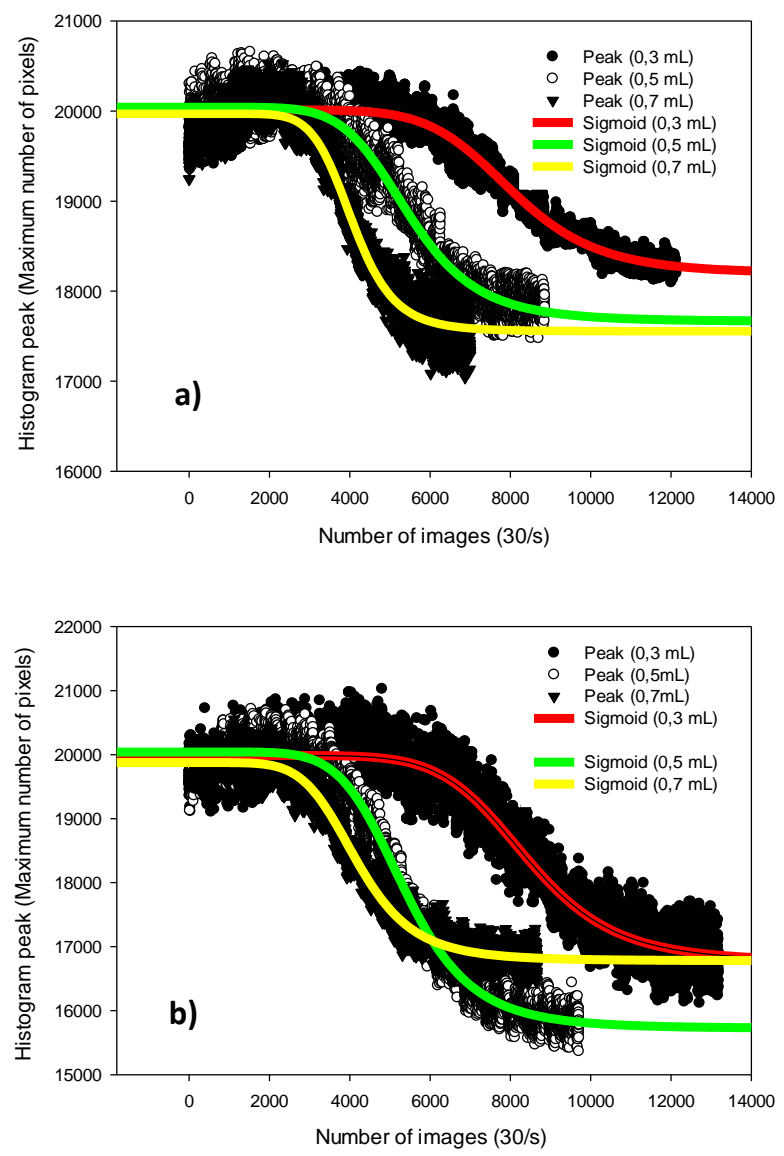

Figure 6: Effects of rennet level on milk coagulation:

a) Raw cow milk

b) Skim milk powder.

Figs. 7a, b show curves of evolution of the RGB color histogram peak in images milk coagulation supplemented with $0.01 \mathrm{M}$ calcium for $0.3 \mathrm{~mL}$ of rennet at three experiment temperatures $(30,33 \text { et } 36)^{\circ} \mathrm{C}$. While Figs. $8 \mathrm{a}$, b show plots of variation of the RGB color histogram peak in images milk coagulation supplemented with $\mathrm{CaCl}_{2}(0.01,0.02$ and 0.03$) \mathrm{M}$ for $0.3 \mathrm{~mL}$ of rennet at $30^{\circ} \mathrm{C}$. The changes in these parameters as a function of coagulation time show that curves obtained presented three phenomena: (i) a relatively constancy in the histogram peak, (ii) a rapid decrease and (iii) a stabilization of 


\section{Processing"}

the parameters. The photometric coagulation measurement measures the relative transmission of light in the range of visible, which is passed through a coagulating milk sample. A camera detects the transmitted signal and the relative transmission is evaluated through image sequences analysis (histogram peak). The latter parameter decreases over the coagulation process due to increased absorption and scattering of the light as the milk structure changes [42]. For milk supplemented with $0.01 \mathrm{M}$ at $30^{\circ} \mathrm{C}$, the histogram peak began to deviate from the baseline after approximately $66.67 \mathrm{sec}$ after the addition of rennet, decreased rapidly and then levelled off after approximately $300 \mathrm{sec}$. The midpoint of this transition occurs after approximately $200 \mathrm{sec}$ after addition of $0.3 \mathrm{~mL}$ rennet, even in our raw cow milk and the control skim milk powder. At approximately $66.67 \mathrm{sec}$, the histogram peak curve shows a decrease. This could be attributed to the beginning of the formation of the network from gel precursors, where the aggregates of micelles form small patches/particles of gel. This leads to the observed increase of light scattered, as the size of the particles became comparable with the light wavelength (850 nm) [42]. According to Hardy and Fanni [43], generally, light diffusion caused by suspended particles in a liquid medium follows Rayleigh's law for particles smaller than about 1/4 the wavelength of light. For these particles, diffusion is proportional to the cube of their diameter. As the particle diameter increases, diffusion decreases inversely with the square of the particle diameter. According to these laws, diffusion reaches a maximum level when particle size becomes about $1 / 4$ the wavelength of light.

These presented results showed that milk optical parameters varied during rennet-induced coagulation. The survey of the coagulation of milk and the proteins of the soy from the color was already carried out by some researchers [15, 44]. The results obtained by Dybowska and Fujio [44], on the optical analysis of the coagulation of proteins of soy with the glucono- $\delta$-lactone, permitted to understand that $\mathrm{L}^{*}, \mathrm{a}^{*}$ and $\mathrm{b}^{*}$ values grow during the time and decrease according to the $\mathrm{pH}$ during the coagulation. The dimension of soy proteins aggregated increased with the increase of the intensity of light reflection. Research work performed by Lagaude et al. [22] on the optical method of characterization of rennet milk coagulation proved that the number and the average area of particles varied during rennet coagulation. They demonstrated that the number of particles decreased while the average area of particles increased during the same time. The increase of the intensity of light reflection, consequently reduces the light intensity transmitted through the renneted milk image sequences.

\subsection{Coagulation time determination}

\subsubsection{Method of Berridge}

All experiments were carried out with two different methods using raw cow milk and skim milk powder. The times of coagulation were determined for three different quantities of rennet and presented in Table 1. Table 2 presented values obtained for different added calcium concentrations, while Table 3, contains values for three different assay temperatures. Times corresponding to the same quantity of rennet, the same added calcium and the same assay temperature present no statistical meaningful difference $(P<0.05)$.
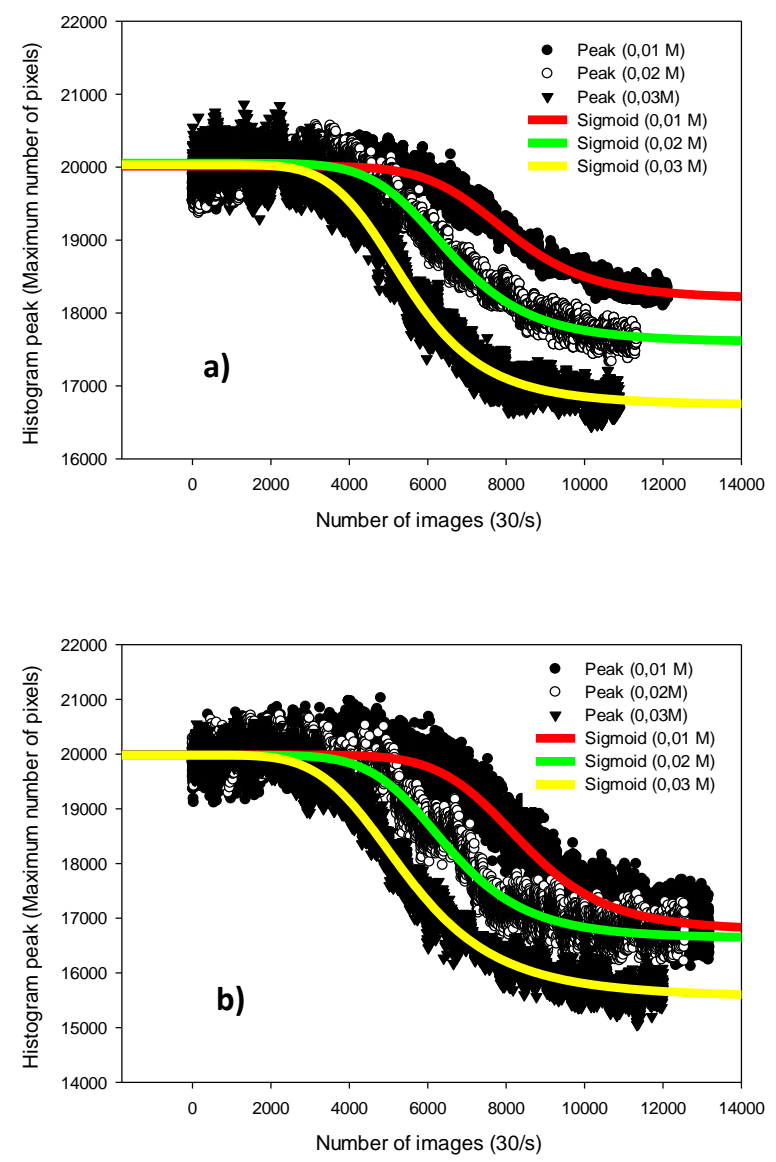

Figure 7: Effects of added calcium on the histogrampeak, as measured by the image sequences histogram analysis method, as a function of time in rennettreated milk added calcium levels were: $0.01 \mathrm{M}$, $0.02 \mathrm{M}, 0.03 \mathrm{M}$ :

a) Raw cow milk

b) Skim milk powder.

\subsubsection{Method based on image sequences processing}

$\mathrm{T}_{\mathrm{F}}$ was determined as shown in Tables 1, 2 and 3 according to the approach previously described for three quantities of rennet, different added calcium concentrations and three different assay temperatures, respectively.

\subsubsection{Rennet-induced milk coagulation times analysis}

The histogram peak in image sequences enable the determination of the milk coagulation time $\left(\mathrm{T}_{\mathrm{C}}\right)$ both, by the method of Berridge and by the approach described in this paper. It resulted from Tables 1, 2 and 3 that no statistically significant differences were found in rennet coagulation time measurements in either of the studied methods $(\mathrm{P}>0.05)$, while at $36^{\circ} \mathrm{C}$, there was a significant difference. There occurred statistically non-significant differences in most of the measurements, comparing both methods. The results show that 


\section{Processing"}

the proposed optical method based on measurement of changes in histogram peak is a potential objective method for $T_{C}$ measurement.

Table 1: Effect of rennet level on $\mathrm{T}_{\mathrm{C}}$ values as obtained for rennet-treated milk at $30^{\circ} \mathrm{C}$ with added Calcium of $0.01 \mathrm{M}$

\begin{tabular}{|c|c|c|c|c|}
\hline \multicolumn{5}{|c|}{ Milk coagulation times $(\mathrm{s})$} \\
\hline \multirow[b]{2}{*}{$\begin{array}{c}\text { Rennet } \\
\text { quantity } \\
(\mathrm{mL})\end{array}$} & \multicolumn{2}{|c|}{ Berridge method } & \multicolumn{2}{|c|}{ Images sequences analysis } \\
\hline & $\begin{array}{c}\text { Raw cow } \\
\text { milk }\end{array}$ & $\begin{array}{c}\text { Skim milk } \\
\text { powder }\end{array}$ & $\begin{array}{c}\text { Raw cow } \\
\text { milk }\end{array}$ & $\begin{array}{c}\text { Skim milk } \\
\text { powder }\end{array}$ \\
\hline 0.3 & $\mathrm{a}^{\mathrm{a}}$ & $\mathrm{d}^{\mathrm{d}}$ & $a^{a}$ & ${ }^{d}$ \\
\hline 0.3 & $272.33 \pm 4.04$ & $277.30 \pm 3.05$ & $269.50 \pm 3.19$ & $273.23 \pm 5.19$ \\
\hline 0.5 & $188.33 \pm 3.06$ & $182.67 \pm 4.16$ & $182.49 \pm 4.08$ & $179.13 \pm 4.83$ \\
\hline 0.7 & $141.33 \pm 3.21^{c}$ & $148.67 \pm 3.50$ & $136.10 \pm 2.73^{\mathrm{c}}$ & $14035+473^{\mathrm{f}}$ \\
\hline
\end{tabular}

${ }^{\text {abcdef }}$ means with different superscripts within each row are different $(P<0.05)$.

Table 2: Effect of added calcium on $\mathrm{T}_{\mathrm{C}}$ values as obtained for rennet-treated milk

\begin{tabular}{|c|c|c|c|c|}
\hline \multicolumn{5}{|c|}{ Milk coagulation times (s) } \\
\hline \multirow[b]{2}{*}{$\begin{array}{l}\text { Calcium } \\
\text { addition } \\
\text { (M) }\end{array}$} & \multicolumn{2}{|c|}{ Berridge method } & \multicolumn{2}{|c|}{$\begin{array}{l}\text { Images sequences } \\
\text { analysis }\end{array}$} \\
\hline & $\begin{array}{l}\text { Raw cow } \\
\text { milk }\end{array}$ & $\begin{array}{l}\text { Skim milk } \\
\text { powder }\end{array}$ & $\begin{array}{c}\text { Raw cow } \\
\text { milk }\end{array}$ & $\begin{array}{c}\text { Skim milk } \\
\text { powder }\end{array}$ \\
\hline 0.01 & $272.33 \pm 4.04$ & $277.30 \pm 3.05$ & $269.50 \pm 3.19^{\mathrm{a}}$ & $273.23 \pm 5.19$ \\
\hline 0.02 & $222.33 \pm 3.06^{b}$ & $223.00 \pm 5.29^{\mathrm{e}}$ & $221.66 \pm 2.78^{\mathrm{b}}$ & $217.57 \pm 4.30^{\mathrm{e}}$ \\
\hline 0.03 & $187.67 \pm 2.52^{c}$ & $184.33 \pm 4.04^{\mathrm{f}}$ & $182.76 \pm 5.67^{\mathrm{c}}$ & $181.20 \pm 3.1{ }^{\mathrm{f}}$ \\
\hline
\end{tabular}

${ }^{\text {abcdef }}$ means with different superscripts within each row are different $(P<0.05)$.

Table 3: Effect of coagulation temperature on $\mathrm{T}_{\mathrm{C}}$ values as obtained for rennet-treated milk

\begin{tabular}{|c|c|c|c|c|}
\hline \multicolumn{5}{|c|}{ Milk coagulation times (s) } \\
\hline \multirow[b]{2}{*}{$\begin{array}{l}\text { Tempe } \\
\text { rature } \\
\left({ }^{\circ} \mathbf{C}\right)\end{array}$} & \multicolumn{2}{|c|}{ Berridge method } & \multicolumn{2}{|c|}{ Images sequences analysis } \\
\hline & $\begin{array}{l}\text { Raw cow } \\
\text { milk }\end{array}$ & $\begin{array}{c}\text { Skim milk } \\
\text { powder }\end{array}$ & $\begin{array}{c}\text { Raw cow } \\
\text { milk }\end{array}$ & $\begin{array}{c}\text { Skim milk } \\
\text { powder }\end{array}$ \\
\hline & $\mathrm{a}$ & $d$ & $\mathrm{a}$ & $d$ \\
\hline 30 & $272.33 \pm 4.04$ & $277.30 \pm 3.05$ & $269.50 \pm 3.19$ & $273.23 \pm 5.19$ \\
\hline 33 & $231.67 \pm 4.51_{\mathrm{c}}$ & $228.50 \pm 4.04_{\mathrm{f}}$ & $226.60 \pm 5.60$ & $224.07 \pm 2.12_{h}$ \\
\hline 36 & $196.67 \pm 3.06$ & $196.33 \pm 3.51$ & $186.37 \pm 4.33$ & $187.83 \pm 3.06$ \\
\hline
\end{tabular}

$\overline{\text { abcdefgh }}_{\text {means with different superscripts within each row are }}$ different $(P<0.05)$.

The proposed method seems very robust, objective and more accurate than the Berridge method which is subjective because it depends on an operator's skill to consistently identify milk flocculation. It should be noted that the times obtained by image sequences analysis were slightly lower than the times determined by the method of Berridge. It means that image sequences analysis is very sensitive to the phenomenon and quickly detects milk coagulation time before the method of Berridge.

To validate the approach dealt with image sequences analysis method using histogram quaternion-type representation, the effect of the rennet level, assay temperature and calcium concentration on the enzymatic coagulation of raw cow and skim milk powder was followed using both the image sequences analysis method and the Berridge method (Tables 1, $2,3)$. These factors are known to affect the rennet coagulation: the addition of $\mathrm{CaCl}_{2}$ to the milk in the concentration range of $0-10 \mathrm{mM}$ increases the overall enzymatic coagulation rate $[22$, $45,46]$ and increasing the temperature from $26^{\circ} \mathrm{C}$ to $40^{\circ} \mathrm{C}$ reduces the gelation time $[12,22,46]$. Indeed, it is well known that temperature affects both the primary (enzymatic hydrolysis) and secondary (aggregation reaction) phase of milk [47]. The results presented in Figs. 7a,b and Figs. 8a,b are in agreement with those reported in the literature cited above. Although method carried out by Djaowé et al. [29] was reliable to calculate milk coagulation time, however this marginal method is faced some kind of limitation: As stated by Alfsmann et al. [35], the sample as whole conveys information, that could be lost if the components of the sample are processed independently. In addition, according to Wang et al. [48], the quaternion-based models treat color image as a multivector in the quaternion form and preserve the relationships of the multiple channels to avoid the loss of structures information among different channels. According to $\mathrm{Xu}$ et al. [49] too, differing from traditional separated and concatenated monochrome models, which consider only a fraction of the subspaces that are needed for completely representing a vectorsensor array, the quaternion-based model can preserve the whole information of a 3D vector array. Furthermore, comparing to the tensor-based model, the quaternion-based model not only preserves the correlation among channels, but also the orthogonal property for the coefficients of different channels, which achieves a structured representation.

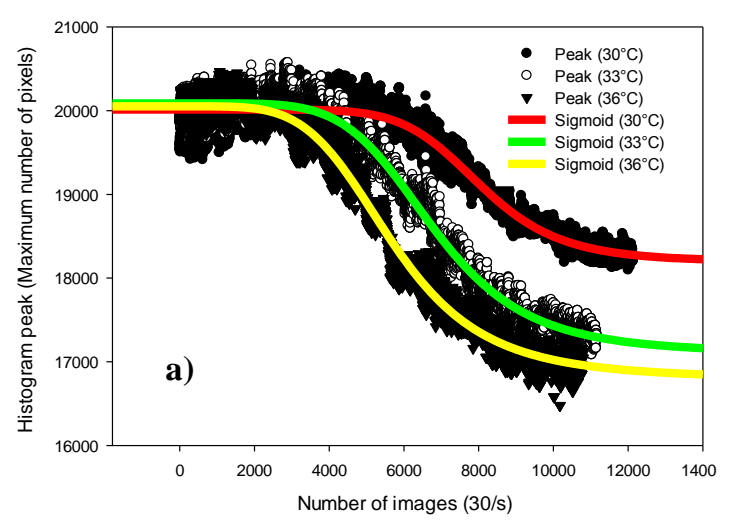




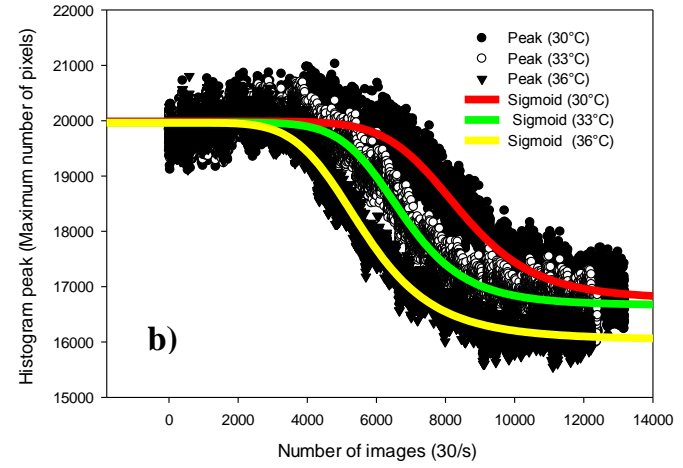

Figure 8: Effects of temperature on the histgram peak, as measured by the image sequences histogram analysis method.

a) Raw cow milk

b) Skim milk powder.

\section{CONCLUSION}

The rennet coagulation of milk was followed using optical microscopy coupled with image sequences analysis using quaternion type representation. The decrease in the histogram peak observed by this microscopic image sequences analysis method allowed the determination of one important information for controlling curd formation: the coagulation time $\left(\mathrm{T}_{\mathrm{C}}\right)$. The determination of $\mathrm{T}_{\mathrm{C}}$ measured using Berridge method and the image sequences analysis method described herein gave values not significantly different even if the milk samples were supplemented with calcium $(0.01-0.03 \mathrm{M})$ or coagulated at different temperatures $\left(30-33^{\circ} \mathrm{C}\right)$, except at $36^{\circ} \mathrm{C}$ where values of coagulation times are significantly different. It should be noted that the times obtained by image sequences analysis were slightly lower than the times determined by the method of Berridge. It means that image sequences analysis is very sensitive to the phenomenon and quickly detects milk coagulation time before the method of Berridge. The proposed method seems very robust, objective and more accurate than the Berridge method which is subjective because it depends on an operator's skill to consistently identify milk flocculation. Due to the accuracy and the simplicity of the experimentation, this method could be easily automated and applied to characterize milk clotting enzymes and to study changes in the physical state of other polymers.

\section{ACKNOWLEDGEMENTS}

We are greatly indebted to the Cameroon Government for funding the research through the Ministry of Higher Education. The assistance of Bianzi Pierre from the Food Physicochemistry Laboratory of ENSAI is gratefully appreciated.

\section{REFERENCES}

1. Kübarsepp, I., Henno, M., Kärt, O., Tupasela, T. A comparison of the methods for determination of the rennet coagulation properties of milk. Acta
Agriculturae Scandinavica, Section A-Animal Science. 55, 145-148 (2005).

2. Jõudu, I., Henno, M., Kaart, T., Püssa, T., Kärt, O. Effect of milk protein contents on the rennet coagulation properties of milk from individual cows. International Dairy Journal. 18, 967-970 (2008).

3. Benguigui, L., Emery, J., Durand, D., Busnel, J.P. Ultrasonic study of milk clotting, Lait. 74, 197-206 (1994).

4. Gunasekaran, S., Ay, C. Milk coagulation cut-time determination using ultrasonics. Journal of Food Process Engineering. 19, 63-73 (1996).

5. Nassar, G., Nongaillard, B., Noel, Y. Monitoring of milk gelation using a low-frequency ultrasonic technique. Journal of Food Engineering. 48, 351-359 (2001).

6. Izbaim, D., Faiz, B., Moudden, A., Taifi, N., Aboudaoud, I. Contrôle ultrasonore du processus de fermentation du yaourt in $10^{\text {ème }}$ Congrès Français d'Acoustique, Lyon, 12-16 avril, France (2010).

7. Castillo, M. Cutting time prediction methods in cheese making. Encyclopedia of Agricultural, Food, and Biological Engineering. 1-7 (2006).

8. Klandar, A.H., Lagaude, A., Chevalier-Lucia, D. Assessment of the rennet coagulation of skim milk: A comparison of methods. International Dairy Journal. 17, 1151-1160 (2007).

9. Berridge, N.J. An improved method of observing the clotting of milk containing rennin. Journal of Dairy Research. 9, 328-329 (1952).

10. McMahon DJ, Brown RJ. Evaluation of Formagraph for comparing rennet solutions. Journal of Dairy Sciences. 65, 1639-1642 (1982).

11. Karacheviev Y, Angelova T, Yordanova D Karabashev V. Modelling of Buffalo Milk Coagulation Kinetics after Addition of Enzymes at Different Concentrations by Means of Mechanical Lactodynamography. International Journal of Current Research Acadamy and Review. 6(9), 1-11 (2018).

12. Lucey $\mathbf{J}$ A. Formation and physical properties of milk protein gels. Journal of Dairy Sciences. 85, 281-294 (2002).

13. O'Callaghan DJ, O'Donnell CP, Payne FA. On-line sensing techniques for coagulum setting in renneted milks. Journal of Food Engineering. 43, 155-165 (2000).

14. Bamelis FR, De Baerdemaeker JG. Use of the FoodTexture Puff Device to monitor milk coagulation. Journal of Dairy Sciences. 89, 29-36 (2006).

15. O'Callaghan DJ, O'Donnell CP, Payne FA. Review of systems for monitoring curd setting during 
cheesemaking. International Journal of Dairy Technology. 55, 65-74 (2002).

16. Sbodio OA, Tercero EJ, Coutaz R, Martinez E. Optimizing processing conditions for milk coagulation using the Hot Wire method and response surface methodology. Journal of Food Sciences. 67, 197-1102 (2002).

17. Smykov IT. Milk curd cutting time determination in cheesemaking. Food systems. 1(2), 12-20 (2018).

18. Fagan CC, Leedy M, Castillo M, Payne FA, O'Donnell CP, O'Callaghan DJ. Development of a light scatters sensor technology for on-line monitoring of milk coagulation and whey separation. Journal of Food Engineering. 83, 61-67 (2007).

19. Rovira S, García V, López MB. Application of a Large Field-of-View sensor during coagulation and syneresis in fresh goat cheese manufacture. International Journal of Dairy Technology. 65(1), 5156 (2012).

20. Pytel R, Šustová K, Kumbár V, Nedomová Š. A comparison of the determination of the rennet coagulation properties of bovine milk. Potravinarstvo Scientific Journal for Food Industry. 10(1), 366-371 (2016).

21. Beux S, Pereira EA, Cassandro M, Nogueira A, Waszczynskyj N. Milk coagulation properties and methods of detection, Ciência Rural. 47(10), 1-8 (2017).

22. Lagaude A, Fernandez L, Cuq J-L, Marchesseau S. Characterization of curd formation during the rennet coagulation of milk by an optical microscopic method. International Dairy Journal. 14, 1033-1039 (2004).

23. Legrand L, Marzani F, Dusserre L. Etude quantitative des mouvements du cœur sur des séquences d'images angiographiques. Informatique et Santé. 5, 155-166 (1992).

24. Jähne B, Haussecker H, Hering F, Platt U, Schurr U, Stitt M. Image Sequences Analysis to Investigate Dynamic Processes. Progress Report Phase I (12/1995-2/1998) (1998).

25. Lefèvre S, Holler J, Vincent N. Segmentation temporelle de séquences d'images en couleurs compressées et non compressées en temps réel. Publication de l'équipe RFAI : Congrès francophone ORASIS de Vision par Ordinateur, Cahors (France), Juin, 329-338 (2001).

26. Nakroshis $\mathrm{P}$, Amoroso $\mathrm{M}$, Legere J, Smith C. Measuring Boltzmann's constant using video microscopy of Brownian motion. American Journal of Physics. 71(6), 568-573 (2003).

27. Ionescu B, Lambert $P$, Coquin D, Buzuloiu V. The Cut Detection Issue in the Animation Movie Domain. Journal of multimedia. 2(4), 10-19 (2007).
28. Adhikari P, Gargote N, Digg J, Hogade BG. Abrupt Scene Change Detection. World Academy of Science, Engineering and Technology. 42, 711-716 (2008).

29. Djaowé G, Bitjoka L, Boukar O, Libouga DG, Waldogo B. Measurement of the rennet clotting time of milk by digital image sequences $(2 \mathrm{D}+\mathrm{t})$ processing. Journal of Food Engineering. 114, 235241 (2013).

30. Lambert P, Chanussot J. Extending mathematical morphology to color image processing. Proc. of first International Conference on Color in Graphics and Image Processing, (CGIP'2000). October, SaintEtienne, France (2000).

31. Sangwine SJ. Colour in Image Processing. Electronics and Communication Engineering Journal. 12 (5), 211-219 (2000).

32. Moxey CE, Sangwine SJ, Ell TA. Vector Correlation of colour Images in First European Conference on Colour in Graphics, Imaging and Vision (CGIV 2002), University of Poitiers, France, 2-5 April, The society for Image Science and Technology. 343-347 (2002).

33. Denis P, Carré P, Fernandez-Maloigne C. Spatial and spectral quaternionic approaches for Color Images. Computer Vision and Image Understanding. 107, 74 87 (2007).

34. Ell TA, Sangwine SJ. Hypercomplex Fourier transforms of color images. IEEE Transactions on. Image Processing. 16, 22-35 (2007).

35. Alfsmann D, Göckler HG, Sangwine SJ, Ell TA. Hypercomplex algebras in digital signal processing:Benefits and drawbacks. In 15th European Signal Processing Conference (EUSIPCO 2007), September 3-7, Poznan, Poland (2007).

36. Endrizzi I, Fabris A, Biasioli F, Aprea E, Franciosi E, Poznanski E, Cavazza A, Gasperi F. The effect of milk collection and storage conditions on the final quality of Trentingrana cheese: Sensory and instrumental evaluation. International Dairy Journal. 23, 105-114 (2012).

37. Mahieddine B, Nesrine F, Farah M, Nabila D, Ines F, Lynda T, Nadia M, Redouane Z. Caractérisation du lait de chèvre produit dans la région du Nord-Est Algérien. Essai de fabrication du fromage frais. Algerian Journal of Natural Products. 5(2), 492-506 (2017).

38. Edima HC, Awono ET, Ndjouenkeu R. An Analysis of the Milk Quality in Cameroon. A Study in Adamawa Region. Journal of Scientific Research \& Reports. 2(1), 337-346 (2013).

39. Adetunji VO, Babalobi OO. A comparative assessment of the nutritional contents of 'wara' a West African soft cheese using calotropis procera and cymbopogon citratus as coagulants. African Journal 
of Food, Agriculture, Nutrition and Development.

11(7), 5573-5585 (2011).

40. Lezoray O, Elmoataz A, Cardot H, Revenu M. Segmentation d'images couleur: Application en microscopie cellulaire. Traitement du Signal, Lavoisier. 17(1), 33-45 (2000).

41. Ghernaout D, Al-Ghonamy AI, Boucherit A, Ghernaout B, Naceur MW, Messaoudene NA, Aichouni M, Mahjoubi AA, .Elboughdiri NA. Brownian motion and Coagulation Process. American Journal of Environmental Protection. 4(5-1), 115(2015).

42. Dwyer C, Donnelly L, Buckin V. Ultrasonic analysis of rennet-induced pre-gelation and gelation processes in milk. Journal of Dairy Research. 72, 303-310 (2005).

43. Hardy J, Fanni J. Application of reflection photometry to the measurement of milk coagulation. Journal of Food Sciences. 46, 1956-1957 (1981).

44. Dybowska BE, Fujio Y. Optical Analysis of Glucono\&-Lactone Induced Soy Protein Gelation. Journal of Food Engineering. 38, 123-133 (1998).

45. Bencini R. Factors affecting the clotting properties of sheep milk. Journal of the Science of Food and Agriculture. 82, 705-719 (2002).

46. Najera AI, de Renobales M, Barron LJR. Effects of $\mathrm{pH}$, temperature, $\mathrm{CaCl}_{2}$ and enzyme concentrations on the rennet clotting properties of milk: A multifactorial study. Food Chemistry. 80, 345-352 (2003).

47. McMahon DJ, Brown RJ. Development of surface functionality of casein particles as the controlling parameter of enzymic milk coagulation. Colloids and Surfaces. 44, 263-279 (1990).

48. Wang R, Wang K, Cao W, Wang X. Geometric Algebra in Signal and Image Processing: A Survey. IEEEAccess. 7, 156315-156325 (2019).

49. Xu Y, Yu L, Xu H, Zhang H, Nguyen T. Vector Sparse Representation of Color Image Using Quaternion Matrix Analysis. IEEE Transactions on Image Processing. 24(4), 1315-1328 (2015). 